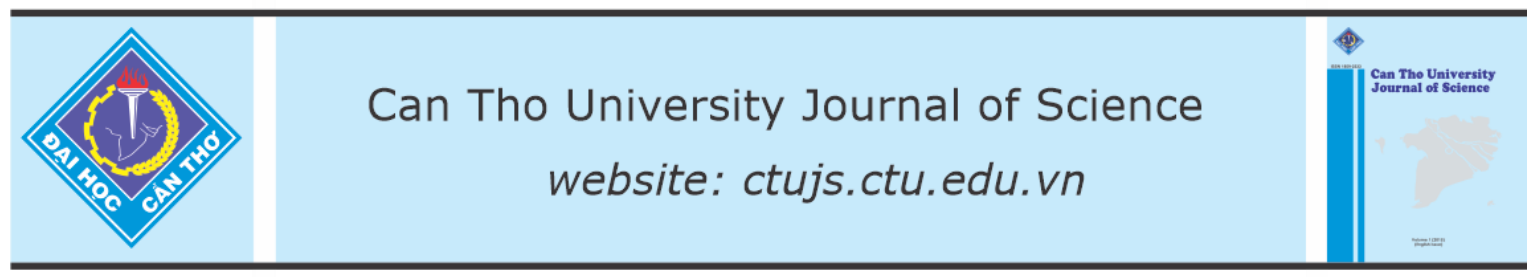

DOI: 10.22144/ctu.jen.2021.041

\title{
Optimization of the encapsulation of the mixture made from flesh and peel pitaya extract by spray drying
}

\author{
Duong Thi Ngoc Diep*, Hoang Quang Binh and Do Le Hanh Trang \\ Faculty of Chemical Engineering and Food Technology, Nong Lam University, Ho Chi Minh City, Viet Nam \\ *Correspondence: Duong Thi Ngoc Diep (email: duongngocdiep@hcmuaf.edu.vn)
}

\section{Article info.}

Received 17 May 2021

Revised 13 Jun 2021

Accepted 27 Jul 2021

\section{Keywords}

Optimization, maltodextrin, spray dried pitaya powder, inlet air drying temperature

\begin{abstract}
In this study, the optimal conditions for spray drying of the extract made from flesh and peel of red pitaya were tested using the central composite design (CCD). The response surface methodology was used to evaluate the effect of inlet air drying temperature $\left(145-155^{\circ} \mathrm{C}\right)$ and concentration of maltodextrin $(13-17 \% \mathrm{w} / \mathrm{w})$ on the physicochemical properties of the powder. The regression models accurately predicted the retention of betacyanin $\left(R^{2}=0.94\right)$ and total phenolic $\left(R^{2}=0.95\right)$. The optimal conditions for spray drying were determined as inlet air drying temperature at $148^{\circ} \mathrm{C}$ and $14.62 \%$ maltodextrin. Under these conditions, the spray-dried powder achieved retention of betacyanin of $68.04 \%$ and retention of total phenolic of $84.17 \%$. The optimized sample achieved a moisture content of $4.41 \%$, the water activity of 0.39 , and the water solubility index of $97.41 \%$.
\end{abstract}

\section{INTRODUCTION}

The pitaya has a high bioactive compound such as vitamins C, fiber, betacyanin, and polyphenols (Nurul \& Asmah, 2014). Besides, the flesh of the fruit has an attractive colors including red, purplered color. Many authors have studied red flesh pitaya microencapsulation by spray-drying (Lee et al., 2013; Tze et al., 2012). However, the ingredient most commonly used was flesh. The previous study showed that peel takes $25-30 \%$ in whole fruit weight. It meant, after processing, a large number of peels were discarded, which put a high pressure on the environment. Moreover, several studies observed pitaya peel had antioxidant capacity and a potential source of natural colorants (Wu et al., 2006; Stintzing et al., 2002).

There are numerous reports finding inlet temperature and maltodextrin concentration are one most of the main factors, that strongly influence spray-dried powder's quality (Bakar et al., 2013; Phisut, 2012; Goula \& Adamopoulos, 2008). However, there is limited scientific information on how these factors can affect the physicochemical properties of red pitaya powder made from a mixture include flesh and peel extracts.

In many studies, response surface methodology (RSM) has been widely applied to optimize dry processing (Bakar et al., 2013; Tan et al., 2015). Therefore, the present study was carried out to understand the influence of inlet temperature and maltodextrin concentration on retention of betacyanin and total phenolic of red pitaya fruit powder by using RSM. The physical properties of optimal powder as moisture content, water activity, and solubility were evaluated. 


\section{MATERIALS AND METHODS}

\subsection{Material and chemical}

Red-flesh pitaya fruits (Hylocereus polyrhizus) were purchased at Thu Duc wholesale market, Ho Chi Minh city. The selected fruit was free of physical injures, rotten. The selected fruits were seprerated peel and flesh, next, each part was packed by polyamide bags coated aluminum and stored at $18^{\circ} \mathrm{C}$.

Chemical: Gallic acid, Folin - Ciocalteu 99,5\% (Merck, Germany), sodium carbonate $98 \%$ (Xilong, China).

\subsection{Sample preparation}

\subsubsection{Extraction preparation}

The flesh after thawing was ground by a juicer (MJ$70 \mathrm{M}$, Panasonic, Japan), then mixed with water to the ratio of 1:1 (w/w). Pectinex Ultra SP-L of $0.2 \%$ (weight/weight of flesh) concentration was added. The puree was hydrolyzed at $\mathrm{pH}$ natural (4.0-4.5), temperature $45^{\circ} \mathrm{C}$ for 60 minutes in a water bath (Schutzurt, Germany). After that, the sample was inactivated at $100^{\circ} \mathrm{C}$ for $1 \mathrm{~min}$, then filtered through a cheesecloth. The obtained solution was refrigerated at $10^{\circ} \mathrm{C}$ until use.

The peel was mixed with distilled water to the ratio of $1: 1(\mathrm{w} / \mathrm{w})$ and crushed by a blender. Pectinex Ultra SP-L of $0.4 \%$ (weight/weight of peel) concentration was added into the peel solution. The mixture was hydrolyzed at $\mathrm{pH}$ natural (4.8-5.0), temperature $45^{\circ} \mathrm{C}$ for a period of 90 minutes. After that, the samples were inactivated at $100^{\circ} \mathrm{C}$ for 1 $\mathrm{min}$, then centrifuged at $5000 \mathrm{rpm}$ for $10 \mathrm{mins}$ and filtered through a cheese cloth to get the peel extract. The obtained solution was refrigerated at $5-7{ }^{\circ} \mathrm{C}$ until use.

\subsubsection{Preparation of spray drying infeed solution}

The mixture includes flesh extract and peel extract with a ratio of $4: 1(\mathrm{w} / \mathrm{w})$, its total soluble solid is $5.0-5.5 \%$. The mixture was added to the different amounts of the maltodextrin DE 10 to reach the desired concentration (Table 1). The mixtures were mixed well by using a homogenizer at $5000 \mathrm{rpm}$ for 5 mins (T18 digital Ultra Turrax homogenizer, IKA, Germany. All samples were prepared in a coated beaker aluminum to prevent light. The initial sample temperature was room temperature $\left(29-31^{\circ} \mathrm{C}\right)$

\subsubsection{Spray drying condition}

The mixtures were conducted using a laboratoryscale spray dryer (KD-400, the machine was invented by the Department of Chemical, at campus Ho Chi Minh city of Nong Lam University). For each inlet solution, $200 \mathrm{~mL}$ was sprayed through a nozzle tip. The samples were dried at several inlet temperatures (Table 1), and the feed flow rate was set at $500 \mathrm{~mL} / \mathrm{h}$ which was controlled by the pump rotation speed at $2.5 \mathrm{rpm}$ and compressor air pressure of $2.1 \mathrm{kgf} / \mathrm{cm}^{2}$. Next, the encapsulated powders were collected and kept in a screw-capped amber bottle and stored at $-18^{\circ} \mathrm{C}$ until further analysis.

All parameter of each step preparation were collected from the result of the preliminary test.

\subsection{Experiment design}

The RSM with central composite design (CCD) was used to find the spray drying condition optimal condition of the inlet air drying temperature $\mathrm{X}_{1}$ (from $145^{\circ} \mathrm{C}$ to $155^{\circ} \mathrm{C}$ ) and the concentration of maltodextrin $\mathrm{X}_{2}$ (from $13 \%$ to $17 \%$ ), in order to achieve the highest retention of betacyanin content and total phenolic. The experiment consisted of 11 runs with three central points. The levels for the independent variables were displayed in Table 1. The sample which was optimal was determining physical properties such as bulk density, water activity, color measurement, water solubility index, moisture content.

Table 1. Variable values of the parameters

\begin{tabular}{crc}
\hline Coded levels & $\mathbf{X}_{\mathbf{1}}$ & $\mathbf{X}_{\mathbf{2}}$ \\
\hline-1 & 145 & 13 \\
0 & 150 & 15 \\
+1 & 155 & 17 \\
\hline
\end{tabular}

$X_{1}$ : Inlet air drying temperature $\left({ }^{\circ} \mathrm{C}\right) \mathrm{X}_{2}$ : Concentration of maltodextrin

\subsection{Analytical method}

\subsubsection{Determination of moisture content}

The moisture content of the powder was determined by using MX-50 moisture analyzer.

\subsubsection{Determination of water activity}

The water activity was measured using a water activity meter (Aqualab Series 3, Decagon, WA, USA). 


\subsubsection{Determination of betacyanin content}

The betacyanin quantification was determined by using a spectrophotometer (Herbach et al., 2007). Absorption spectrum of betacyanin was determined at a wavelength of $538 \mathrm{~nm}$. Betacyanin content (mg/g dry matter) was calculated by the following equation:

\section{Betacyanin content $(\mathrm{mg} / 100 \mathrm{~g}$ dry matter $)=$ $\frac{A \times D F \times V \times M W \times 100 \times 100}{\varepsilon \times L \times W(100-\text { Moisture content })}$.}

Where: $\mathrm{A}$ is the absorption value at the absorption maximum $\left(\lambda_{\max }=538 \mathrm{~nm}\right)$. DF is the dilution factor. MW is the molecular weight of betanin $(550 \mathrm{~g} / \mathrm{mol})$. $\mathrm{V}$ is the pigment solution volume $(\mathrm{mL}) . \varepsilon$ is the molar extinction coefficient of betanin $(\varepsilon=60,000$ $\mathrm{L} \mathrm{mol}^{-1} \mathrm{~cm}^{-1}$ in $\mathrm{H}_{2} \mathrm{O}$ ). $\mathrm{L}$ is the pathlength of the cuvette $(\mathrm{L}=1 \mathrm{~cm})$. W is the weight of dried material (g). 100: the coefficient converts from g to $100 \mathrm{~g}$

\subsubsection{Determination of total phenolic content (TPC)}

This method according to Lim et al. (2007). Aliquot $1 \mathrm{~mL}$ of each of these dilutions were mixed with 10 $\mathrm{mL}$ of distilled water and then with $0.5 \mathrm{ml}$ of FolinCiocalteu reagent $10 \%$ and allowed to stand for 6 minutes. Then $1.5 \mathrm{~mL}$ of $20 \%$ sodium carbonate and $1 \mathrm{~mL}$ of distilled water were added to the reaction mixture. The absorbance was recorded after 2 hours in dark conditions at $760 \mathrm{~nm}$ spectrometrically. Total phenolic contents (TPC) were expressed in term of gallic acid equivalent mgGAE /100 $\mathrm{g}$ of dry matter $(\mathrm{dm})$

$$
T P C=\frac{(y-b) \times V \times D F \times 100 \times 100}{a \times m \times(100-\text { moisture content }) \times 1000}
$$

Where y: OD of sample. $a$ and $b$ are the coefficient in the standard curve. $\mathrm{V}$ : volume of extracted solution. DF: dilution factor. m: mass of sample $(\mathrm{g})$. 100/1000: the coefficient converts from $\mu \mathrm{g} / \mathrm{g}$ to $\mathrm{mg} / 100 \mathrm{~g}$.

\subsubsection{Determination of bioactive compound's retention}

Proportion of betacyanin or total phenolic retained $=\frac{B c_{1}}{B c_{o}}$, Where $\mathrm{Bc}_{\mathrm{o}}$ represents the betacyanin or total phenolic content before storage and $\mathrm{Bc}_{1}$ represents the betacyanin or total phenolic content after storage.

\subsubsection{Color measurement}

The color was determined using a Minolta Chroma Meter calibrated with a white standard tile. The results were expressed as Hunter colour values of $\mathrm{L}^{*}, \mathrm{a}^{*}$, and $\mathrm{b}^{*}$, where $\mathrm{L}^{*}$ was used to denote lightness, $\mathrm{a}^{*}$ redness and greenness, and $\mathrm{b}^{*}$ yellowness and blueness.

\subsubsection{Water solubility index (WSI)}

Spray-dried pitaya powder $(0.5) \mathrm{g}$ was mixed with 6 $\mathrm{ml}$ of distilled water into a centrifuge tube. After continuously stirring for $30 \mathrm{~min}$ in water bath at $30^{\circ} \mathrm{C}$, the suspension was centrifuged at $3000 \mathrm{rpm}$ for $10 \mathrm{~min}$. The supernatant was placed in a petri dish and dried at $105^{\circ} \mathrm{C}$ for 4 hours to obtain the dry solids weight (Anderson et al., 1969). The WSI (\%) was calculated as the percentage of dried supernatant with respect to the amount of the original $0.5 \mathrm{~g}$ pitaya powder:

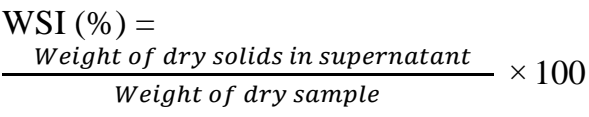

\subsection{Statistical analysis}

All data of this study were calculated by using Microsoft Excel software version 2016, and analysis of variance (ANOVA) was carried out by using JMP 13. The results were reported as mean \pm standard deviations and all experiments were carried out 2 times.

\section{RESULTS AND DISCUSSION}

\subsection{Fitting the Response Surface Methodology (RSM) model to independent variables}

The betacyanin retention of all samples was in the range of $62.56 \%-71.20 \%$, with an average of $67.82 \%$. On the other hand, the total phenolic retention for 11 runs was in the range of $69,54 \%$ $84,51 \%$, with an average of $77,28 \%$ (Table 2). There was a clear positive interaction between the retention of betacyanin and total phenolic. This means that the powder obtained low betacyanin's retention with low total phenolic's retention (run 7), and high betacyanin's retention with high total phenolic's retention (run 9). 
Table 2. The experimental values for the percentage retention of betacyanin and total phenolic (TPC) for the encapsulated red pitaya powder made from the flesh and peel extract mix obtained from the RSM-CCD design

\begin{tabular}{|c|c|c|c|c|c|c|c|}
\hline \multirow{2}{*}{$\begin{array}{c}\text { Experiment } \\
\text { number }\end{array}$} & \multirow{2}{*}{ Pattern } & \multirow{2}{*}{$\begin{array}{c}\mathrm{X}_{1} \\
\text { Tempe-rature } \\
\left({ }^{\circ} \mathrm{C}\right)\end{array}$} & \multirow{2}{*}{$\begin{array}{c}\mathrm{X}_{2} \\
\text { Concen-tration } \\
\%(\mathrm{w} / \mathrm{w})\end{array}$} & \multicolumn{2}{|c|}{ Betacyanin $(\%)$} & \multicolumn{2}{|c|}{ TPC (\%) } \\
\hline & & & & Exp. & Pred. & Exp. & Pred. \\
\hline 1 & $\overline{--}$ & 145 & 13 & 68.58 & 68.75 & 79.18 & 79.39 \\
\hline 2 & $\mathrm{a} 0$ & 145 & 15 & 71.05 & 69.75 & 80.68 & 80.96 \\
\hline 3 & -+ & 145 & 17 & 65.82 & 66.95 & 73.46 & 72.96 \\
\hline 4 & $0 \mathrm{a}$ & 150 & 13 & 68.63 & 69.27 & 79.11 & 79.72 \\
\hline 5 & 00 & 150 & 15 & 70.30 & 71.04 & 83.38 & 82.97 \\
\hline 6 & 00 & 150 & 15 & 70.98 & 71.04 & 83.65 & 82.97 \\
\hline 7 & 00 & 150 & 15 & 71.20 & 71.04 & 84.51 & 82.97 \\
\hline 8 & $0 \mathrm{~A}$ & 150 & 17 & 70.32 & 69.03 & 74.64 & 76.66 \\
\hline 9 & +- & 155 & 13 & 62.56 & 61.75 & 69.54 & 68.72 \\
\hline 10 & A0 & 155 & 15 & 63.66 & 64.31 & 71.32 & 73.67 \\
\hline 11 & ++ & 155 & 17 & 62.91 & 63.07 & 70.57 & 69.04 \\
\hline
\end{tabular}

$X_{I}$ : The inlet air drying temperature; $X_{2}$ : Maltodextrin concentration. (+) Upper limit value, (-) Lower limit value, (a) High axis value, (A) Low axis value, (0) Value at midpoint

Overall, the correlation between the inlet temperature level and the retention of betacyanin and TPC was negatively correlated at independent variable $\left(\mathrm{X}_{1}\right)$, quadratic variable $\left(\mathrm{X}_{12}\right)$, and reverse at interaction variable $\left(\mathrm{X}_{1} \mathrm{X}_{2}\right)$. Similar finding for the concentration of maltodextrin (Table 3 ).

As determined using the p-value, the coefficients of the retention of betacyanin and TPC for the inlet temperature were directly related and the maltodextrin concentration inversely related. However, the coefficients of the retention of betacyanin and TPC were all significant for the second - order quadratic effects, with both the inlet temperature and the maltodextrin concentration (Table 3). The final equations in terms of the two independent variables, inlet air drying temperature $\left(\mathrm{X}_{1}\right)$ and maltodextrin concentration $\left(\mathrm{X}_{2}\right)$ for retentions of betacyanin and TPC to obtain the predicted values in Table 3 were as follows:

$Y_{1}=-3396.23+46.53 X_{1}+2.51 X_{2}+0.08 X_{12}-$ $0.16 \mathrm{X}_{1}^{2}-0.47 \mathrm{X}_{2}^{2}(1)$

$Y_{2}=-4778.68-64.65 X_{1}+9.74 X_{2}+0.17 X_{12}-0.23$

$\mathrm{X}_{1}^{2}-1.20 \mathrm{X}_{2}^{2}$

In which, $Y_{1}$ and $Y_{2}$ are the retentions of betacyanin and total phenolic, respectively; $\mathrm{X}_{1}$ : The inlet air drying temperature, $\mathrm{X}_{2}$ : Maltodextrin concentration.

Table 3 also showed the coefficient of multiple determination for the retention of betacyanin $\left(\mathrm{R}^{2}=\right.$ $0.94)$, and TPC $\left(R^{2}=0.95\right)$ were high. The $R^{2}$ value shows the closest relation between the experimental and prediction values, which confirm the accuracy of the model and the existence of the optimal point. On the other hand, $94 \%$ and $95 \%$ of the change in the retention of betacyanin and TPC are influenced by independent factors such as drying temperature and maltodextrin concentration. According to Castillo (2007), the $\mathrm{R}^{2}>0.75$ presents that the model is compatible with the experiment. It means the second-order polynomial models (equations 1 and 2 ) could be used for calculating the experimental data.

Table 3. The coded second-order regression coefficients for the retention of betacyanin and total phenolic (TPC) for the encapsulated flesh and peel pitaya powder obtained from the RSM CCD design

\begin{tabular}{|c|c|c|}
\hline \multirow{2}{*}{$\begin{array}{l}\text { Independent } \\
\text { Variables }\end{array}$} & \multicolumn{2}{|c|}{ Regression Coefficient Values } \\
\hline & Betacyanin (\%) & ТPC (\%) \\
\hline Intercept & $71.04 * *$ & 82.97 \\
\hline \multicolumn{3}{|c|}{ Linear } \\
\hline $\mathrm{X}_{2}$ & -0.12 & -1.53 \\
\hline $\mathrm{X}_{1}$ & $-2.72 *$ & $-3.65 * *$ \\
\hline \multicolumn{3}{|c|}{ Quadratic } \\
\hline $\mathrm{X}_{2} \mathrm{X}_{2}$ & $-1.90 *$ & $-4.78 * *$ \\
\hline $\mathrm{X}_{1} \mathrm{X}_{1}$ & $-4.02 *$ & $-5.66 * *$ \\
\hline \multicolumn{3}{|c|}{ Interaction } \\
\hline$\overline{X_{1} X_{2}}$ & 0.78 & 1.69 \\
\hline $\mathrm{R}^{2}$ & 0.94 & 0.95 \\
\hline$p-$ value of lack of fit & 0.096 & 0.063 \\
\hline
\end{tabular}

$X_{1}$ : The inlet temperature of the air drying; $X_{2}$ :

Maltodextrin concentration; *: $p<0.05 ; * *: p<0.01$. 


\subsection{Effects of the air drying temperatures on maltodextrin concentrations on retention of betacyanin and total phenolic}

In the present study, Table 2 and the 3D response surface (Figure 1) illustrated that the retention of betacyanin and TPC significantly increased under

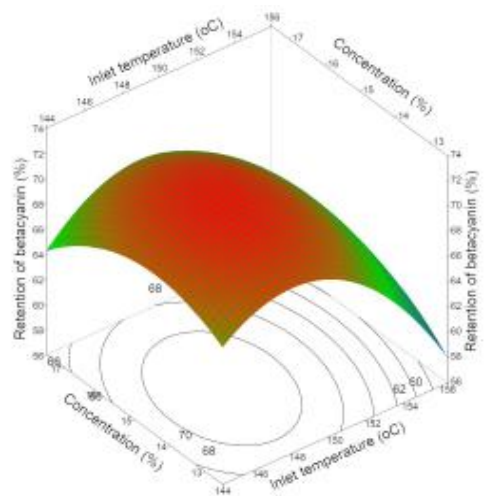

A the inlet temperature from $145^{\circ} \mathrm{C}$ to $150^{\circ} \mathrm{C}$, and the maltodextrin concentration from $13 \%$ to $15 \%$. However, the inlet temperature and the concentration of the encapsulating agents over this range gave a large loss of the bioactive compounds in spray-dried pitaya extract. That one similar trend was reported by Tze et al. (2012).

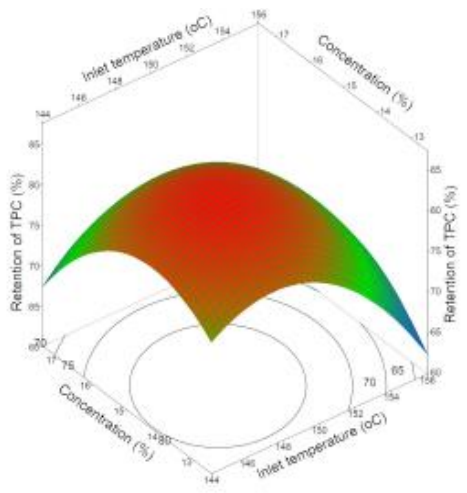

B

Figure 1. The 3D response surface of the retentions of (A) betacyanin and (B) total phenolic content (TPC) of powder (flesh and peel) in response to inlet temperature $\left(X_{1}\right)$ and maltodextrin concentration $\left(X_{2}\right)$

These behaviors could be explained, at inlet temperature higher, the speed of heat transfer to the particle was faster, leading to moisture evaporation more, which helped the liquid convert powder greater. In addition, the agglomeration of maltodextrin with a certain concentration may reduce thermal degradation and oxidation and therefore, protecting the bioactive compounds in red pitaya from destruction. However, in another study, the authors found the betacyanin compound more deteriorated under high temperature (Wong \& Siow, 2015; Liaotrakoon et al., 2013). Moreover, the high amount of maltodextrin could be increasing the viscous infeed solution, which causes the maltodextrin's polymerization difficult, thereby reducing betacyanin and polyphenol content in powder.

\subsection{The Optimal Formulation and Validation of the Models}

The theoretical maximum value for the optimal formulation was predicted to be inlet temperature $\left(\mathrm{X}_{1}\right)$ of $148^{\circ} \mathrm{C}$ and maltodextrin concentration $\left(\mathrm{X}_{2}\right)$ of $14.62 \%$ of the pitaya powder processing (Figure 2 ). These values were close to the predicted value by the quadratic model.

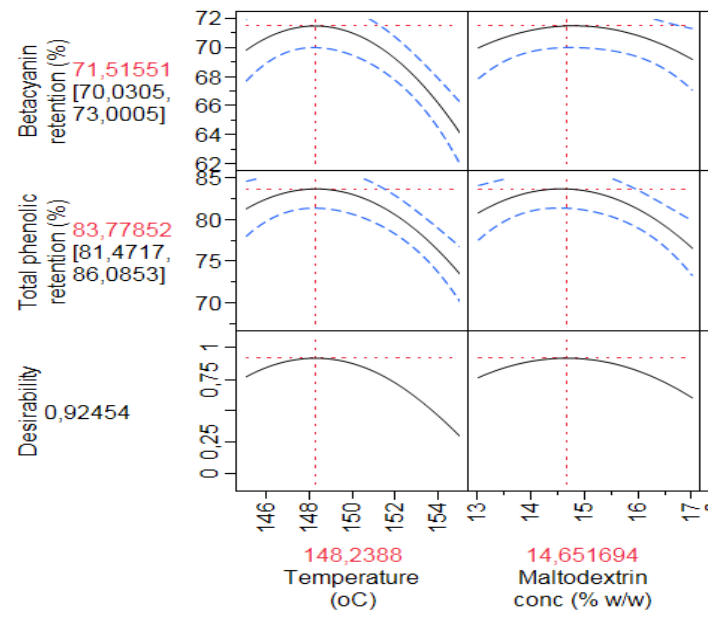

Figure 2. Prediction profiler plots for the retention of betacyanin, total phenolic content (TPC) of the encapsulated flesh and peel extract mix powder affected by inlet air drying temperature $\left(X_{1}\right)$ and maltodextrin concentration $\left(\mathbf{X}_{2}\right)$

The optimal drying conditions to obtain the different fruit powder slightly higher than the conditions were found in this study. For instance, the inlet temperature and maltodextrin concentration for blueberry were $140^{\circ} \mathrm{C}$ and $30 \%$, respectively (Lingua et al., 2020), for bayberry were $50^{\circ} \mathrm{C}$ and $31 \%$, repestively (Liu et al., 2017) and acerola and 
seriguela juice mix powder were $140^{\circ} \mathrm{C}$ and $20 \%$ (Ribeiro et al., 2018). The difference could be explained by the different components of raw material, equipment, dextrose value of drying aid, etc.

Table 4. Predicted and experimental values of the optimum experimental conditions for the retentions of the betacyanin and total phenolic (TPC) for the flesh and peel pitaya powder

\begin{tabular}{lcr}
\hline Parameters & $\begin{array}{r}\text { Predicted Experimental } \\
\text { values }\end{array}$ & values \\
\hline $\begin{array}{l}\text { Inlet temperature }\left(\mathrm{X}_{1}\right) \\
\left({ }^{\circ} \mathrm{C}\right)\end{array}$ & 148.23 & 148 \\
\hline $\begin{array}{l}\text { Maltodextrin } \\
\text { concentration }(\%)\end{array}$ & 14.62 & 14.62 \\
\hline $\begin{array}{l}\text { Retention of betacyanin } \\
(\%)\end{array}$ & 71.51 & $68.04 \pm 0.25$ \\
\hline $\begin{array}{l}\text { Retention of total } \\
\text { phenolic }(\%)\end{array}$ & 83.79 & $84.17 \pm 2.42$ \\
\hline
\end{tabular}

\subsection{Physical properties of the Optimised Encapsulated Powder}

The SEM of flesh and peel powder result showed the pitaya powder particles were spherical in shape, which had a little difference in particle size. As seen in Figure 3, its micrograph exhibited a continuous wall free of crack or pore on the surface. This meant its characteristic to avoid the bioactive compounds of powder being degraded by external factors (temperature, atmosphere...) during spray drying, storage, transportation. Most of the particles were wrinkled in morphology. The surface particle of powder in this study had consistently with the previous study, for instance, the morphology of the pitaya flesh powder with $20 \%$ maltodextrin had a smooth surface appearance (Tze et al., 2012);

The analysis results in Table 5 showed that the optimal pitaya powder in this work had a moisture content of $4.51 \%$ and water activity was 0.32 . Under these conditions, the sample could be stable under the effect of microorganisms as well as the disadvantageous chemical reaction (Labuza, 1970, cited by Pittia \& Antonello, 2016). These results were similar to those of other spray dried fruit powder such as tomato (Goula \& Adamopoulos, 2008), bitter melon (Tan et al., 2015), or pitaya fruit powder (Tze et al., 2017).

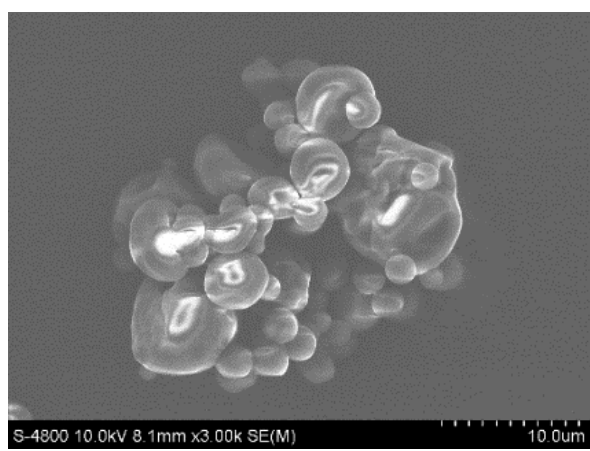

The sample was sent to the nano laboratory of the Research and Development Center, placed in Hi-tech zone, Thu Duc city, Ho Chi Minh city.

Figure 3. SEM of the encapsulated flesh and peel powder prepared with the optimal formulation, $14.62 \%(\mathrm{w} / \mathrm{w})$ maltodextrin and inlet temperature $148^{\circ} \mathrm{C}$ at magnifications of $x$ 3000

The water solubility capacity of encapsulated powder was high $(97,41 \%)$. Its value was higher than bitter melon powder 93.2\% (Tan et al., 2015), mango power $92-95 \%$ (Cano-Chauca et al., 2005). The powder component had maltodextrin, which had high water solubility due to pitaya powder easily dissolved in water (Cano-Chauca et al., 2005). That desirable attribute gave a pitaya powder distributed very well into a product, which improved the utilization ability of powder in the food processing such as beverage and consistency products.

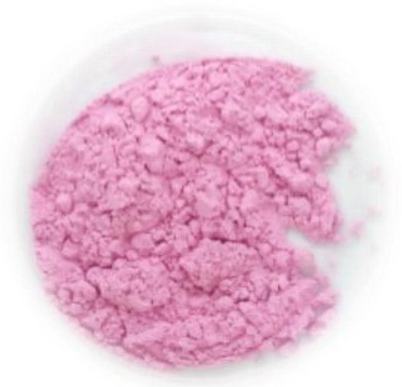

Figure 4. The encapsulated flesh and peel pitaya powder under the optimal formulation: inlet temperature $\left(148^{\circ} \mathrm{C}\right)$ and maltodextrin concentration $(\mathbf{1 4 . 6 2 \%})$

Figure 4 illustrated the optimal powder got bright pink color, which desirable attribute increased application possibilities of red pitaya powder into the food processing as a food colorant. 
Table 5. Predicted and actual values of the optimum experimental conditions for the retentions of the betacyanin and total phenolic (TPC) for the flesh and peel powder

\begin{tabular}{|c|c|c|}
\hline \multicolumn{3}{|c|}{ Physical Properties } \\
\hline Moistu & nt $(\%)$ & $4.51 \pm 0.31$ \\
\hline Water & & $0.32 \pm 0.04$ \\
\hline Water s & $y$ index $(\%)$ & $97.83 \pm 0.29$ \\
\hline \multirow{3}{*}{ Colour } & Lightness & $73.00 \pm 0.41$ \\
\hline & $a^{*}$ & $27.23 \pm 0.38$ \\
\hline & $b^{*}$ & $359.81 \pm 0.02$ \\
\hline
\end{tabular}

\section{CONCLUSION}

The coefficient of the quadratic model for the retention of betacyanin and TPC was found. The

\section{REFERENCES}

Anderson, R.A.; Conway, H.F.; Pfeifer, V.F., \& Griffin, J.R. (1969). Gelatinization of corn

grits by roll and extrusion cooking. Cereal Science Today, 14, 4-12.

Bakar, J., Ee, S. C., Muhammad, K., Hashim, D. M., \& Adzahan, N. (2013). Spray-drying

optimization for red pitaya peel (Hylocereus polyrhizus). Food and Bioprocess Technology, 6(5), 1332-1342. https://doi.org/10.1007/s11947-012$0842-5$

Cano-Chauca, M., Stringheta, P. C., Ramos, A. M., \&Cal-Vidal, J. (2005). Effect of the carriers

on the microstructure of mango powder obtained by spray drying and its functional characterization. Innovative Food Science and Emerging Technologies, 6(4), 420-428. https://doi.org/10.1016/j.ifset.2005.05.003

Del Castillo, E. (2007). Process optimization: a statistical approach (Vol. 105). Springer

Science \& Business Media.

Goula, A. M., \& Adamopoulos, K. G. (2008). Effect of maltodextrin addition during spray

drying of tomato pulp in dehumidified air: II. Powder properties. Drying Technology, 26(6), 726-737. https://doi.org/10.1080/07373930802046377

Herbach, K.M., Maier, C., Stintzing, F.C. \& Carle, R. (2007). Effects of processing and storage

on juice colour and betacyanin stability of purple pitaya (Hylocereus polyrhizus) juice. European Food Research and Technology, 224(5), 649-658. https://doi.org/10.1007/s00217-006-0354-5

Labuza, T. P. (1970). Water content and stability of low moisture and intermediate moisture

foods. Food Technology, 24, 543-550. optimal formulation was predicted and confirmed to be inlet temperature $148^{\circ} \mathrm{C}$ and concentration of maltodextrin $14.62 \%$ of spray-dried pitaya made from extract mixture of flesh and peel. Under these conditions, the encapsulated optimal of flesh and peel powder achieved the retention of betacyanin and total phenolic were $68.04 \%$ and $84.17 \%$, respectively. The optimum of flesh and peel powder had a low moisture content and water activity value, high bulk density, and water solubility index.

\section{ACKNOWLEDGMENT}

The authors would like to thank Nong Lam University for support to this study (project CSSV19-CNTP-01)

Lee, K. H., Wu, T. Y., \& Siow, L. F. (2013). Spray drying of red (Hylocereus polyrhizus) and

white (Hylocereus undatus) dragon fruit juices: Physicochemical and antioxidant properties of the powder. International journal of Food Science and Technology, 48(11), 2391-2399. https://doi.org/10.1111/ijfs.12230

Liaotrakoon, W., De Clercq, N., Van Hoed, V., Van de Walle, D., Lewille, B., \& Dewettinck,

K. (2013). Impact of thermal treatment on physicochemical, antioxidative and rheological properties of white-flesh and red-flesh dragon fruit (Hylocereus spp.) purees. Food and Bioprocess Technology, 6(2), 416-430. https://doi.org/10.1007/s11947-011-0722-4

Lim, Y. Y., Lim, T. T., \& Tee, J. J. (2007). Antioxidant properties of several tropical fruits: A

comparative study. Food Chemistry, 103(3), 1003-1008. https://doi.org/10.1016/j.foodchem.2006.08.038

Lingua, M. S., Salomón, V., Baroni, M. V., Blajman, J. E., Maldonado, L. M., \& Páez, R.

(2020). Effect of Spray Drying on the Microencapsulation of Blueberry Natural Antioxidants. In Multidisciplinary Digital Publishing Institute Proceedings 70(1), 26. https://doi.org/10.3390/foods_2020-07683

Liu, Y., Chen, F., \& Guo, H. (2017). Optimization of bayberry juice spray drying process

using response surface methodology. Food Science and Biotechnology, 26(5), 1235-1244. https://doi.org/10.1007/s10068-017-0169-0

Nurul, S. R., \& Asmah, R. (2014). Variability in nutritional composition and phytochemical

properties of red pitaya (Hylocereus polyrhizus) from Malaysia and Australia. International Food Research Journal, 21(4), 1689-1697.

Phisut, N. (2012). Spray drying technique of fruit juice powder: some factors influencing the 
properties of product. International Food Research Journal, 19(4), 1297-1306.

Pittia, P., \& Antonello, P. (2016). Safety by control of water activity: Drying, smoking, and salt

or sugar addition. In Regulating safety of traditional and ethnic foods (pp. 7-28). Academic Press. https://doi.org/10.1016/B978-0-12-800605-4.00002-5

Ribeiro, C. M. C. M., Magliano, L. C. D. S. A., Costa, M. M. A. D., Bezerra, T. K. A., Silva,

F. L. H. D., \& Maciel, M. I. S. (2018). Optimization of the spray drying process conditions for acerola and seriguela juice mix. Food Science and Technology, 39, 48-55. https://doi.org/10.1590/fst.36217

Stintzing, F. C., Schieber, A., \& Carle, R. (2002). Betacyanins in fruits from red-purple pitaya,

Hylocereus polyrhizus (Weber) Britton \& Rose. Food Chemistry, 77(1), 101-106, https://doi.org/10.1016/S0308-8146(01)00374-0

Tan, S. P., Kha, T. C., Parks, S., Stathopoulos, C., \& Roach, P. D. (2015). Optimising the encapsulation of an aqueous bitter melon extract by spray-drying. Foods, 4(3), 400-419, DOI: $10.3390 /$ foods 4030400 . https://doi.org/10.3390/foods4030400

Tze, N. L., Han, C. P., Yusof, Y. A., Ling, C. N., Talib, R. A., Taip, F. S., \& Aziz, M. G.,

(2012). Physicochemical and nutritional properties of spray-dried pitaya fruit powder as natural colorant. Food Science and Biotechnology, 21(3), 675-682. https://doi.org/10.1007/s10068-012-0088-z

Wong, Y. M., \& Siow, L. F. (2015). Effects of heat, pH, antioxidant, agitation and light on

betacyanin stability using red-fleshed dragon fruit (Hylocereus polyrhizus) juice and concentrate as models. Journal of Food Science and Technology, 52(5), 3086-3092. https://doi.org/10.1007/s13197-014-1362-2

Wu, L. C., Hsu, H. W., Chen, Y. C., Chiu, C. C., Lin, Y. I., \& Ho, J. A. (2006). Antioxidant and antiproliferative activities of red pitaya. Food Chemistry, 95(2), 2319-327. https://doi.org/10.1016/j.foodchem.2005.01.002 